\title{
Dental abnormalities in horses
}

\author{
HV Masey O'Neill ${ }^{1,2}$, J Keen ${ }^{2}$, L Dumbell ${ }^{2}$ \\ ${ }^{1}$ University Of Nottingham, Leicestershire, United Kingdom, ${ }^{2}$ Hartpury College, Gloucester, United Kingdom \\ Email: helen.maseyoneill@nottingham.ac.uk
}

Introduction The equine, free grazing at grass, will graze for up to 16 hours a day (Arnold, 1984), depending on seasonal daylight variations in a natural environment. When this time budget is compared to the eating times of modern domesticated and stabled equines, it is easily understood why domestication may adversely affect the essential attrition of horses' teeth. The specific aims of this study were to investigate and compare the prevalence of common abnormalities in the equine dentition between thoroughbred-type horses when stabled and when kept at grass. It is hypothesised that stable kept horses, fed a cereal based diet and therefore spending less time chewing, will have greater prevalence of dental abnormalities than free-living horses.

Materials and methods Two groups of 30 thoroughbred-type horses, aged 5-15 years, both mares and geldings, were used. Group one, 'free-living', were kept at a stock horse stud at Holbrook, New South Wales, Australia. These horses remained at pasture all year round with little human contact. Their diet comprised entirely of grassland. Group two, 'stable kept' were stabled in Gloucestershire, UK. They were stabled for the majority of the day on a bed of wood shavings with rubber matted floor and only removed from the stable for exercise once or twice a day. They were fed a diet consisting of a cereal based compound mix and a hay net twice a day. The two groups underwent a routine dental examination following British Equine Veterinary Association recommended procedures by the same person for both groups. A generic dental chart was completed, which monitored oral health and dental condition and recorded the occurrence of 12 recognised dental abnormalities. These abnormalities are recognised and defined by the British Association of Equine Dental Technicians (BAEDT, 2008) and include Sharp Edges (SE) and Accentuated Transverse Ridges of the occlusal surface of molar arcade (ATR) for example. A count of one was given for recognition of any and each abnormalities, regardless of severity. For example, a horse showing SE and ATR, was given a count of two. No horses had received any dental treatment for at least nine months prior to examination. The data were collected as part of a student's final year placement requirements, and were retrospectively analysed at the University. The difference in occurrence between groups was analysed using a Chi Squared test (Microsoft Office Excel 2003; Microsoft Corporation). The difference in total number of abnormalities per horse in each group was analysed using a Mann-Whitney Test (SPSS version 16; SPSS Inc.).

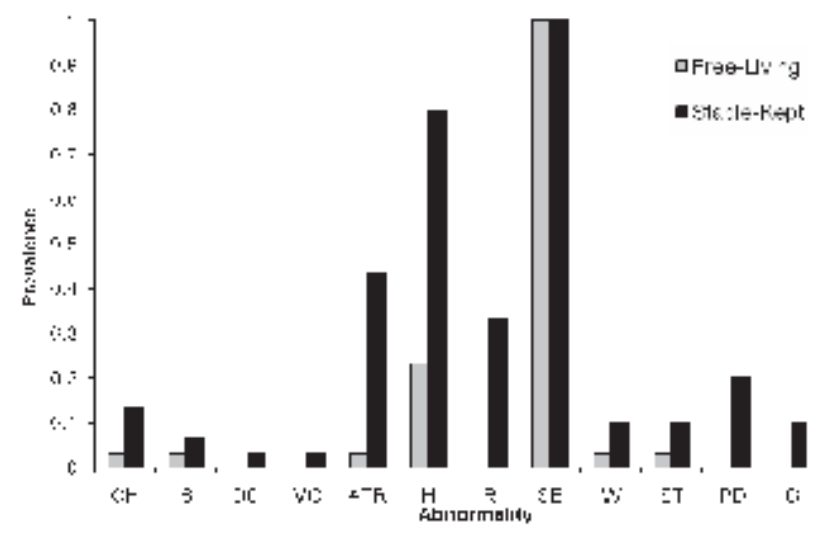

Figure 1 The prevalence of each abnormality

Results There were clear numerical differences in the prevalence of all disorders except sharp edges (SE; see figure 1 which shows the prevalence of each abnormality, as a proportion of group size). All twelve abnormalities were observed in the stable kept group and the occurrence was greater than in free living horses, except in the case of SE $(\mathrm{P}=1)$. Five of the twelve abnormalities were not observed in any free living horses. The difference in occurrence was confirmed to be significant in the case of ATR, Hooks (H) and Ramps $(\mathrm{R})(\mathrm{P}<0.001)$. In total, significantly more dental abnormalities were observed in stable kept horses when compared to free living horses $(p<0.001)$.

Discussion The above observations are of importance as they add weight to the anecdotal argument that a modern equine lifestyle and diet, based on energy dense cereals as opposed to forage, may adversely affect the dentition of the horse, by increasing the prevalence of dental abnormalities. This is particularly interesting when considered with the observation that there is no difference between the occurrence of sharp edges between free-living and stable-kept horses. Sharp edges are considered to be detrimental and would commonly be removed by an EDT during dental correction (Ralston et al., 2001). The result of our study potentially suggests that this particular abnormality is not induced solely by a lack of forage and may also suggest that further work is required to decide if routine removal of sharp edges is actually a necessity. This being said, there is clearly merit in preventing and removing such abnormalities that begin to cause pain and potentially lead to infection. A scoring system, that indicates the severity of an abnormality could be developed, incorporating a cut off point at which routine procedures are necessary. The stable kept horses were fed forage as part of their ration, so the effect of masticating this kind of material was not totally removed. However, when eating from a hay net, the teeth are not aligned in the same way in which they would be in a grazing horse and this may affect normal teeth attrition. It has also been suggested by Tell et al., (2008) that the use of a bridle can increase dental abnormalities, although in this particular study, ulceration was the focus.

\section{References}

Arnold, G. W. 1984. Applied Animal Behaviour Science 13, 19-30.

BAEDT. 2008. Issues. Retrieved August 82008 from http://www.Baedt.Com/issues.php

Ralston, et al. 2001. Equine Veterinary Journal 33, 390-393

Tell et al. 2008 The Veterinary Journal 178, 405-410 